bright lines were also found in the spot spectrum, and between $C$ and $D$ some very peculiar shadings terminated sharply at the less refrangible limit by a hard dark line, but fading out gradually in the other direction at a distance of three or four of Kirchhoff's scale divisions. The interpretation of such markings is not quite clear, but would rather seem to point to such a reduction of temperature over the spot-nucleus as permits the formation of gaseous compounds by elements elsewhere dissociated, since these shaded spectra are quite probably characteristic of non-elementary substances, a view fortified by Schuster's recent beautiful investigations upon the spectrum of nitrogen.

Many more or less remarkable solar eruptions were observed, though none on quite so magnificent a scale as some before recorded. On several occasions velocities of from 150 to 200 miles per second in the ejected matter were observed by means of the displacement and distortion of the hydrogen lines, and on one occasion a velocity of nearly 250 miles was attained. One of the finest erup. tions was visible on the surface of the sun itself in the immediate neighbourhood of a large spot.

A careful comparison of some of these observations with the corresponding magnetic records at Greenwich and Stonyhurst, for copies of which records $I$ am indebted to the courtesy of Sir G. B. Airy and Rev. S. J. Perry, goes far to show that, although probably the greatest magnetic disturbances are due to terrestrial causes, or at least are only indirectly results of solar or cosmical influences, yet, on the other hand, every solar paroxysm does have a distinct, direct, and immediate effect upon the magnetic elements. Thus on August 3 such solar paroxysms were noted at $8.45,10.30$, and II.55, also on August 5 from 6.20 to 7.30 A.M. (Sherman time), and the last was the only outburst during the day.

Now the annexed figure (Fig. I), from a photographic copy of the vertical force curve for these days at Greenwich, shows marked and characteristic disturbances at the points indicated, which, allowing for the longitude, correspond to the very instants when the solar disturbances were noted. Further comparisons of such phenomena will be necessary to establish the conclusion with absolute certainty; but in the meantime it seems altogether probable that every solar disturbance receives an immediate response from the earth, and that the magnetic impulse travels with, sensibly, the velocity of light.

I must not close - without alluding to certain observations that enable us to distinguish, to some extent, between the substances ejected from the sun, and those constituting the atmosphere into which the irruption takes place. Certain lines during these outbursts were distorted and displaced, while others near them, equally conspicuous, were wholly unaffected.

Thus on August 3 and 5, the former class included the lines of hydrogen, $D_{3}$, the lines of sodium, magnesium, and many of those of iron; in the latter were $\mathrm{K}_{534}$, $1474,1505,1515,1528,1867,2007$ (1870 and 200 were intensely disturbed), $258 \mathrm{I}$, and probably the two Hs; I say probably, because the observation of these lines was too difficult to permit absolute certainty, still I feel very confident that they were unaffected. The barium lines also seldom seemed to participate in any disturbance.

The obvious moral of our summer's work seems to me this, that no time ought to be lost in occupying points of such advantage with the most powerful instruments : the great telescopes now building should be put in a position to profit by such atmospheric conditions as will secure their utmost efficiency, for while it is of little consequence to science whether ordinary glasses are placed where their power will be increased by 25 per cent., it may make a difference of years and decades in her advance if the new artillery opens its attack upon the heavens from the mountain-tops instead of from the plains.

Dartmouth College, Nov. 25

\section{THE TRANSIT OF VENUS}

$A T$ the meeting of the Astronomical Society on November 8, a sketch was given of Lord Lindsay's preparations for the forthcoming transit of Venus. Lord Lindsay has selected the island of Mauritius as his station, on account of its highly favourable meteorological conditions. He intends, if possible, to combine the following methods of observation :-I. Observations of the internal contacts to be worked out on the plans of Halley and Delisle. 2. Observations of the first external contact at the chromosphere, to be made with the spectroscope. 3 . Photographic pictures. 4. Heliometric measures. For the longitude it is at present intended to use the transits of the moon with an altazimuth made by Simms. As it is expected that the Germans will also have a station on the Mauritius, Lord Lindsay will connect his station with theirs by triangulation. The transit instrument is by Cooke, and has four inches aperture. The chronograph, which can be kept in motion for four hours, has four barrels, each of which can be worked separately, thus avoiding all confusion. The photographic method to be used is that of Prof. Winlock, who suggests a telescope of 40 feet focal length, placed horizontally, and a heliostat to reflect the sun's image along it. The lens is to be an achromatic one. It is intended to have two planes to the heliostat, one mounted on a polar axis, and another to send the rays down the tube. Lord Lindsay has ordered a Foucault siderostat with 16 -inch mirrors, and has obtained a 13-inch unsilvered mirror to fit the telescope to be taken. out. He intends to use a heliometer, though it is not much in favour in this country, Messrs. Respald, of Hamburgh, having undertaken to make one for him with all the improvements used in the Oxford_instrument, as well as in some others. The Germans intend to send one to Kerguelen Land, and the Russians will use it at Lake Baikal and the mouth of the Amoor. Lord Lindsay's will include the motion of the halves of the object-glass in curved siides, so that the images will remain in focus; unlimited rotation of the tube in the cradle; the measurement of tho position angle at the eye end, and measures of the micrometer read there also. Some new points are ; - the gradua tion of the slides of the object-glass side by side, so as to be read by the same microscope; an arrangement to shat off light from half the object-glass, so as to equalise tho light of the images; and the introduction of a thermometer at the end of the tube. Lord Lindsay proposes to eliminate errors of division as affected by tempcrature, by placing the instrument on one of the collimating piles of his transit circle at home, and heating the room by gas to different temperatures. It is hoped that, by taking a large number of measures, and by taking the most careful precautions, the original error of observation may be reduced to less than $0^{\prime \prime} 5$, and thus make the result one of extreme acctiracy.

Lord Lindsay will be glad to receive the advice and assistance of astronomers accustomed to use the heliometer. Mr. D. Gill will accompany Lord Lindsay, the two cividing the work of observing between them.

\section{THE "CHALLENGER"}

Friday last, Dec. 6, several members of the counci and "the Circumnavigating Committee" of the Royal Society, by invitation of the Lords of the Admiralty, inspected at Sheerness H.M. ship Challenger, which sailed on Saturday on her three or four years' scientific circumnavigating expedition. The Government have all along consulted the Royal Society as to the fitting out of this expedition, and have liberally carried out every suggestion made by the Circumnavigation Committec. The visitors to Sheerness on Friday included many distinguished men of science, ameng them boing Sir W1ltia:n 